\title{
Stage-specific epigenetic gene silencing during thymocyte lineage commitment Ichiro Taniuchi
}

Address: Laboratory for Transcriptional Regulation, RCAI, RIKEN Centre for Integrative Medical Sciences (IMS-RCAI), 1-7-22, Suehiro-cho, Tsurumi-ku, Yokohama, 230-0045, Japan

Email: taniuchi@rcai.riken.jp

Fl000Prime Reports 2013, 5:22 (doi:10.12703/P5-22)

This is an open-access article distributed under the terms of the Creative Commons Attribution-Non Commercial License (http://creativecommons.org/licenses/by-nc/3.0/legalcode), which permits unrestricted use, distribution, and reproduction in any medium, provided the original work is properly cited. You may not use this work for commercial purposes.

The electronic version of this article is the complete one and can be found at: http://fl $000 . c o m / p r i m e / r e p o r t s / b / 5 / 22$

\begin{abstract}
During lineage commitment, precursor cells must establish their signature gene expression programs to endow them with the requisite set of cellular functions. To maintain cellular identity, the gene expression program must be inherited stably by progeny of lineage-committed cells. Epigenetic regulation serves as a central mechanism to maintain such cellular memory. Although a lot of progress has been made in the last decade towards defining the spectrum of epigenetic modifications on histones and DNA, as well as the relevant enzymatic machinery, the mechanisms by which these modifiers are controlled during development remain poorly understood. Gene regulation at the $\mathrm{Cd} 4$ and Thpok loci provides ideal models for developmentally regulated gene silencing. A single transcriptional silencer at each locus establishes heritable, irreversible epigenetic silencing only in lineage-committed cells, whereas the same silencer elements establish a reversible repressive state in precursor cells. The dynamic versus permanent silencing of developmentally regulated loci by the stage-specific functions of silencers will be discussed in the context of cell lineage commitment.
\end{abstract}

\section{Introduction}

The inheritance of a gene expression program that persists beyond cell division is essential to maintain lineage identity. In this regard, epigenetic mechanisms play a major role in stable gene repression, referred to as gene silencing $[1,2]$. Although many of the factors involved in gene silencing have been identified, little is known about the timing of this process during development. Given the necessity of maintaining the plasticity of gene expression in precursors, silencing mechanisms may shift from transient to permanent further along a developmental pathway. Here, I discuss recent advances in our understanding of stage-specific gene silencing at the $C d 4$ and Thpok loci during thymocyte lineage commitment.

\section{Recent advances}

T lymphocytes undergo a highly ordered developmental program in the thymus before they become fully competent "soldiers" of the immune system, defending us against harmful pathogens. Developing thymocytes must also survive two critical selection processes, known as positive selection, during which cells expressing functional T cell antigen receptors (TCR) are selectively maturated, and negative selection, during which "selfreactive" or useless clones are eliminated [3]. After this primary education, T lymphocytes are further taught to have specialized immune functions, a process known as lineage commitment [4]. These lineage-specific properties must be maintained after $\mathrm{T}$ lymphocytes egress from the thymus to be positioned at the frontline of our defenses. Accordingly, the gene expression signature for effector functions, which is established during lineage commitment, must be memorized to maintain cell identity [5]. Over the past decade, it has become clear that epigenetic modifications are essential components of cellular memory, driving the inheritance of gene expression states through cell divisions [1,2]. In particular, an impressive variety of histone modifications has been identified, which serves as a flexible code for regulating gene transcription [6], together with the identification of 
molecules that contain enzymatic activity for catalyzing these modifications [7]. Another epigenetic modification, DNA methylation at CpG dinucleotides, is also a key component of stable gene repression [8]. New studies are uncovering mechanisms for active DNA de-methylation through a TET-family protein $[9,10]$. It is also becoming apparent that there is cross-regulation between covalent histone modifications and DNA methylation $[11,12]$. All of these epigenetic marks can be written and erased by a large arsenal of enzymes, and the resultant modification patterns at a given location are "read" by nuclear factors to modulate gene expression.

A primary mechanism by which epigenetic modifications are translated into gene expression states is through changes in the accessibility of chromatin. Indeed, a densely packed configuration of chromatin, termed heterochromatin, is thought to play an essential role in the stable maintenance of gene repression [13]. Some forms of heterochromatin can be developmentally regulated, permitting more dynamic control of gene expression. A major area of interest is how and when distinct forms of permanent versus dynamic heterochromatin are established, presumably via the action of cisregulatory elements within a given locus.

Two genetic loci that have served as excellent models to study these issues encode the CD4 co-receptor and the ThPOK transcription factor, two important lineagecommitment molecules for T lymphocytes [14]. There are four major thymocyte subsets, which can be defined by stage- and lineage-specific expression of CD4 and $\mathrm{CD} 8$ co-receptors. Immature thymocyte progenitors that migrate to the thymus express neither $\mathrm{CD} 4$ nor $\mathrm{CD} 8$, appearing as $\mathrm{CD}^{-} \mathrm{CD}^{-}$double negative thymocytes. A subset of precursor thymocytes express both CD4 and CD8 co-receptors on their surface (and are thereby referred to as $\mathrm{CD} 4^{+} \mathrm{CD} 8^{+}$double positive thymocytes) before they differentiate into one of two major subsets, $\mathrm{CD} 4^{+} \mathrm{CD} 8^{-}$helper- or $\mathrm{CD} 4^{-} \mathrm{CD} 8^{+}$cytotoxic- $\mathrm{T}$ lymphocytes [15]. Upon exposure to cues for differentiation into the cytotoxic-lineage, the $C d 4$ gene is suppressed via the activity of an intronic transcriptional silencer [16,17], generating the $\mathrm{CD}^{-}{ }^{-} \mathrm{CD} 8^{+}$subset. Production of ThPOK is also inhibited in cytotoxic-lineage cells by a transcriptional silencer element in the Thpok gene $[18,19]$. Thus silencers, rather than known enhancer elements, in the Cd4 and Thpok genes share cytotoxic lineage-specific activity to control their lineage-specific expression. Another commonality in these silencers is their usage of Runx transcription factors to exert their function $[20,21]$. Importantly, using genetic tools that enable us to remove a particular genome region by Cre-mediated site-specific recombination in mice, these cis-elements have been shown to be dispensable after precursors are fully committed to the cytotoxic-lineage, reflecting a stable state of repression, although they are required to establish Cd4 and Thpok silencing [21,22]. Thus, these silencers do their specialized job only during a particular developmental time window when lineage-specific repressive state is determined. However, remarkably, both the $C d 4$ and Thpok silencers have been shown to also function at an earlier stage of thymocyte development [18,22-24]. Repression of $\mathrm{Cd} 4$ in $\mathrm{CD}^{-} \mathrm{CD}^{-}$double negative thymocytes is also regulated by the same silencer element that permanently represses the gene upon commitment to the cytotoxic lineage (see Figure 1).

However, the repressed status of $C d 4$ in these early progenitors is reversible, as demonstrated by its activation at the subsequent $\mathrm{CD} 4^{+} \mathrm{CD}^{+}$stage of development. Similarly, the silencer in the Thpok gene turned out to be functional in precursor thymocytes, preventing premature activation of the gene prior to lineage choice. Furthermore, Thpok repression in these precursor cells is accompanied by the accumulation of trimethylation at the lysine 27 residue on histone $\mathrm{H} 3$, a representative epigenetic mark for a repressive locus [21]. Despite these repressive epigenetic modifications in precursors, the Thpok gene is later activated in developing thymocytes toward the helper-lineage. However, similar to the situation I described for Cd4, the Thpok silencer is required only to maintain repression in precursor cells, but is dispensable after full commitment to the cytotoxic-lineage [21]. Thus, a single silencer element at each of these loci is employed to regulate two distinct modes of gene repression: reversible repression in precursor thymocytes versus irreversible epigenetic gene silencing in fully committed $\mathrm{CD} 8^{+}$cytotoxic T cells. This also suggests that a covalent histone modification (e.g. methylation at lysine 27) that is known to correlate with a repressive state is not necessarily an 'epigenetic' mark for heritable irreversible silencing, at least in the Thpok locus. The mechanisms by which a single silencer can induce these two types of repressive chromatin states, depending on the developmental context, remain to be established. Given that lineage commitment can occur only in post-selection thymocytes that have received TCR-mediated positive selection signals, a plausible scenario is that TCR-based signals may induce new epigenetic pathways that target chromatin associated with $C d 4$ and Thpok for additional modifications that establish permanent repression.

\section{Summary}

Although the molecular mechanisms that underlie stagespecific epigenetic silencing remain elusive, the physiological relevance of this process is clear. Given the essential 
Figure I. Distinct modes of gene repression by the same silencer at distinct stages
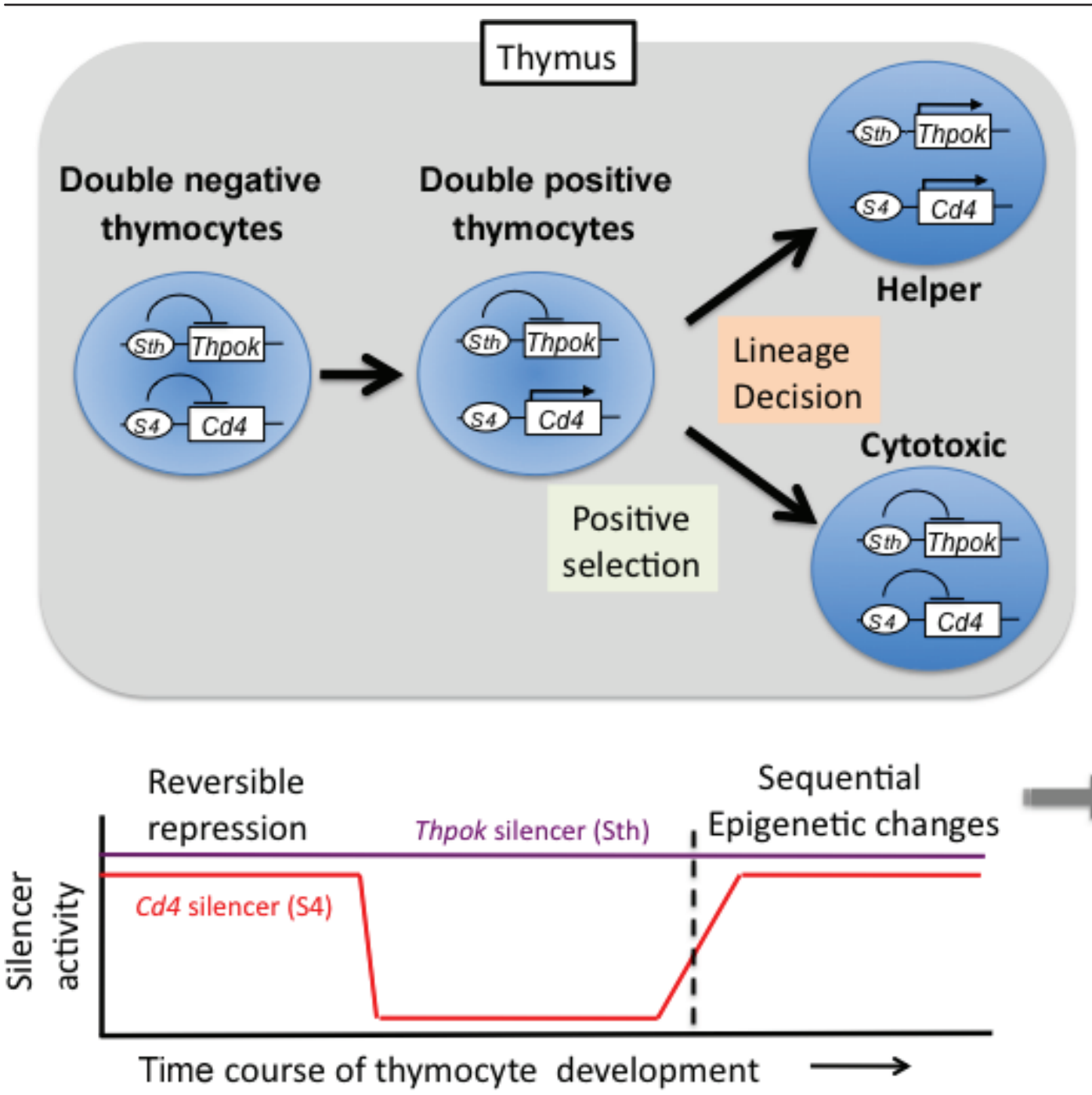

\section{Irreversible stable silencing}

The expression state of the Cd4 and Thpok genes at distinct stages of thymocyte development is illustrated at the top. Relative activities of the Cd4 silencer (S4, red line) and Thpok silencer (Sth, purple line) during thymocyte differentiation towards the cytotoxic lineage are illustrated at the bottom. Whereas both $\mathrm{Cd} 4$ and Thpok genes are repressed in immature double negative thymocytes, the $C d 4$, but not Thpok, gene is expressed in double positive thymocyte precursors. After passing a selection process known as "positive selection", thymocytes choose either a helper or a cytotoxic fate. After this lineage decision, selected cellular identity is maintained, which requires stable inheritance of gene expression status by progeny cells. In order to achieve this, both the Cd4 and Thpok genes receive sequential epigenetic changes through the silencer, eventually resulting in the establishment of gene silencing that can be inherited in the absence of the silencer. Thus, the same silencer can induce reversible gene repression in precursors and irreversible gene silencing in fully committed $\mathrm{CD} 8^{+}$cytotoxic $\mathrm{T}$ cells.

requirement for ThPOK expression in helper $\mathrm{T}$ cell commitment [25], a premature, irreversible repression of Thpok in precursor thymocytes would preclude the generation of helper-lineage cells. Instead, the repressive state of Thpok in precursors must retain plasticity for subsequent gene activation. Thus, a reversible repression at the double positive stages provides flexibility that allows the generation of $\mathrm{CD} 4$ and $\mathrm{CD} 8$ lineages. Once these precursors are exposed to positive selection signals, the plasticity must be transformed to a permanent state of repression in $\mathrm{CD}^{+}$cytotoxic $\mathrm{T}$ cells or the silencer element is disarmed to allow Thpok gene activation in $\mathrm{CD} 4^{+}$helper $\mathrm{T}$ cells. However, there is evidence that epigenetic sealing of the Thpok locus may occur independently from commitment to the cytotoxic T-lineage. Specifically, potentiation of silencer activity at the Thpok locus by increasing the copy number of the silencer element from one to three mediates heritable Thpok silencing even in helper-lineage T cells [21]. Future studies to address this and other mechanisms of silencing at the Cd4 and Thpok 
loci will provide important insights for solving the enigma of how a single silencer element controls reversible and irreversible modes of gene repression at appropriate stages of development.

\section{Abbreviations}

TCR, T cell antigen receptor.

\section{Disclosures}

The author declares that he has no disclosures.

\section{Acknowledgements}

I would like to thank Dr. Eugene Oltz for critical reading of this manuscript.

\section{References}

I. Bonasio R, Tu S, Reinberg D: Molecular signals of epigenetic states. Science 2010, 330:6I2-6I6.

2. Probst AV, Dunleavy E, Almouzni G: Epigenetic inheritance during the cell cycle. Nat Rev Mol Cell Biol 2009, I0:192-206.

3. Germain RN: T-cell development and the CD4-CD8 lineage decision. Nat Rev Immunol 2002, 2:309-322.

4. Singer A, Adoro S, Park JH: Lineage fate and intense debate: myths, models and mechanisms of CD4- versus CD8-lineage choice. Nat Rev Immunol 2008, 8:788-80I.

\section{FlOOOPrime \\ RECOMMENDED}

5. Rothenberg EV, Dionne CJ: Lineage plasticity and commitment in T-cell development. Immunol Rev 2002, I87:96-II5.

\section{FlOOOPrime}

\section{RECOMMENDED}

6. Jenuwein T, Allis CD: Translating the histone code. Science 200I, 293: $1074-1080$

\section{FlOOOPrime}

7. Black JC, Van Rechem C, Whetstine JR: Histone lysine methylation dynamics: establishment, regulation, and biological impact. Mol Cell 2012, 48:49I-507.

\section{FlOOOPrime
RECOMMENDED}

8. Jones PA: Functions of DNA methylation: islands, start sites, gene bodies and beyond. Nat Rev Genet 2012, I 3:484-492.

9. Tahiliani M, Koh KP, Shen Y, Pastor WA, Bandukwala H, Brudno Y, Agarwal S, lyer LM, Liu DR, Aravind L, Rao A: Conversion of 5methylcytosine to 5-hydroxymethylcytosine in mammalian DNA by MLL partner TET I. Science 2009, 324:930-935.

\section{FlOOPrime}

\section{RECOMMENDED}

10. Ito S, D'Alessio AC, Taranova OV, Hong K, Sowers LC, Zhang Y: Role of Tet proteins in $5 \mathrm{mC}$ to $5 \mathrm{hmC}$ conversion, ES-cell self-renewal and inner cell mass specification. Nature 2010, 466: I I29-I I 33.

\section{FlOOOPrime \\ RECOMMENDED}

II. Nan X, Ng HH, Johnson CA, Laherty CD, Turner BM, Eisenman RN, Bird A: Transcriptional repression by the methyl-CpG-binding protein MeCP2 involves a histone deacetylase complex. Nature 1998, 393:386-389.

\section{FlOOOPrime}

12. $\mathrm{Ng} \mathrm{HH}$, Zhang $\mathrm{Y}$, Hendrich B, Johnson CA, Turner BM, ErdjumentBromage $H$, Tempst $P$, Reinberg $D$, Bird A: MBD2 is a transcriptional repressor belonging to the $\mathrm{MeCPI}$ histone deacetylase complex. Nat Genet 1999, 23:58-6I.

\section{FlOOOPrime
RECOMMENDED}

13. Henikoff S: Heterochromatin function in complex genomes. Biochim Biophys Acta 2000, I470:OI-8.

\section{FlOOOPrime}

\section{RECOMMENDED}

14. Taniuchi I, Ellmeier W: Transcriptional and epigenetic regulation of CD4/CD8 lineage choice. Adv Immunol 20I I, I I 0:7 I- I I0.

15. Singer A, Bosselut R: CD4/CD8 coreceptors in thymocyte development, selection, and lineage commitment: analysis of the CD4/CD8 lineage decision. Adv Immunol 2004, 83:9 I - I3 I.

16. Sawada S, Scarborough JD, Killeen N, Littman DR: A lineagespecific transcriptional silencer regulates CD4 gene expression during T lymphocyte development. Cell 1994, 77:917-929.

\section{FlOOOPrime} RECOMMENDED

17. Siu G, Wurster AL, Duncan DD, Soliman TM, Hedrick SM: A transcriptional silencer controls the developmental expression of the CD4 gene. Embo J 1994, I3:3570-3579.

\section{FlOOOPrime}

RECOMMENDED

18. Setoguchi R, Tachibana M, Naoe Y, Muroi S, Akiyama K, Tezuka C, Okuda T, Taniuchi I: Repression of the transcription factor Th-POK by Runx complexes in cytotoxic $T$ cell development. Science 2008, 3 1 9:822-825.

19. He X, Park K, Wang H, He X, Zhang Y, Hua X, Li Y, Kappes DJ: CD4CD8 lineage commitment is regulated by a silencer element at the ThPOK transcription-factor locus. Immunity 2008, 28: 346-358.

\section{FlOOOPrime}

\section{RECOMMENDED}

20. Taniuchi I, Osato M, Egawa T, Sunshine MJ, Bae SC, Komori T, Ito Y, Littman DR: Differential requirements for Runx proteins in CD4 repression and epigenetic silencing during $T$ lymphocyte development. Cell 2002, I I I:62 I-633.

\section{FlOOOPrime}

21. Tanaka H, Naito T, Muroi S, Seo W, Chihara R, Miyamoto C, Kominami R, Taniuchi I: Epigenetic Thpok silencing limits the time window to choose CD4 helper-lineage fate in the thymus. Embo J 2013.

22. Zou YR, Sunshine MJ, Taniuchi I, Hatam F, Killeen N, Littman DR: Epigenetic silencing of CD4 in $\mathrm{T}$ cells committed to the cytotoxic lineage. Nat Genet 200I, 29:332-336.

23. Taniuchi I, Sunshine MJ, Festenstein R, Littman DR: Evidence for distinct CD4 silencer functions at different stages of thymocyte differentiation. Mol Cell 2002, I0:1083-1096.

24. Leung RK, Thomson K, Gallimore A, Jones E, Van den Broek M, Sierro S, Alsheikhly AR, McMichael A, Rahemtulla A: Deletion of the CD4 silencer element supports a stochastic mechanism of thymocyte lineage commitment. Nat Immunol 200I, 2: I|67-II73.

\section{FlOOOPrime
RECOMMENDED}

25. He X, Dave VP, Zhang Y, Hua X, Nicolas E, Xu W, Roe BA, Kappes DJ: The zinc finger transcription factor Th-POK regulates CD4 versus CD8 T-cell lineage commitment. Nature 2005, 433: 826-833. 